\title{
ハイブリッド制御系の一構成法
}

$\begin{array}{llll}\text { 正員 成 清 } & \text { 辰 } & \text { 生 } & \text { (豊田工大) } \\ \text { 正員 泉 } & \text { 照 之 } & \text { (山口大) }\end{array}$

\section{An Architecture of Hybrid Position/Force Control}

Tatsuo Narikiyo, Member (Toyota Technological Institute), Teruyuki Izumi, Member (Yamaguchi University)

Precise control of manipulators in contact with constrains in their environments is a prerequisite to feasible application of robot manipulators to complex handling and assembly problems in industry and space. An important step toward achieving such control is to control simultaneously position and force trajectory. Through recent advances in robotics technology many control design methodologies have been proposed for the control of robot manipulators. The hybrid technique is well known technique in these methodologies. In this technique coordinate system on the constrains plays an important role. But decision scheme of the coordinate system has not been proposed clearly.

This paper analyzes the hybrid technique based on the constrained control system and proposes a new conceptually simple approach to the hybrid technique. The new approach is able to control simultaneously manipulator impedance and position trajectories on the constrains. The coordinate system is appropriately selected and divided into two coordinate systems. These two coordinate systems represent two independent input spaces where the hybrid technique is realized.

Finally we also present the results of experiments that explore application of the hybrid technique to a control of a two degrees of freedom manipulator.

キーワード：ハイブリッド制御，インピーダンス制御，拘束条件，ロボットマニピュレータ

\section{1.はじめに}

ロボットマニピュレータによる作業は，大別して二 つに分けることができる。一つは、ロボットハンドが 自由空間上をある目標軌道に沿って滑らかに運動する 作業である。例えば，組立て作業などが考文られる。 これに対して，鋳物のばり取り作業やクランク回し， はめ合い作業などの上うに，作業対象物（環境）と常 に接触しながら運動する作業がある。これは，コンプ ライアントマニピュレーションと呼ばれ，位置と力の 制御が必要となる作業である。ロボットの制御技術の 進歩に伴い，最近では，積極的に力と位置を同時に制 御することが試みられている。その代表的な例とし て,インピーダンス制御(1)ー(3)や八イブリッド制御(4)(5)

電学論D, 110 巻 11 号, 平成 2 年
と呼ばれる制御系構成法がある。インピーダンス制御 は，力を制御する方向と位置を制御する方向が同一な 場合に有効であると言われている。逆に，八イブリッ ド制御は力と位置の制御の方向が直交するような場合 に多く適用されている。現実に力制御が要求される作 業では, 力と位置の制衔方向は直交する場合が多いと 考えられる。しかし，これに対応すべき，八イブリッ ド制御系の構成法には，まだ，あいまいな部分が残さ れている。文献 (5)では, 動的ハイブリッド制御の一 般的な構成法が示されているが, 拘束面上での作業座 標の選び方が明確に示されていない。

本論文では, 拘束条件付力学系の概念に基づく八イ ブリッド制御系の構成法を示す。この構成法では，口 ボットハンドが拘束される拘束面の法線方向にインピ 
ーダンス調節機能をもち，その拘束面の接平面上で位 置制御を実行できるように拘束面上での作業座標を選 択できる。この座標系の選択法は拘束条件にのみ依存 して损り，実際の作業対象物とそれと独立な仮想拘束 条件を用いることによって容易に拘束面上の局所座標 系を導出できることを示す。また，この座標系は二つ の座標系に分離でき，それぞれの座標系に対して独立 に制御入力を加えることによって，八イブリッド制御 系の構成が可能になることを示す。

最後に，2 自由度マニピュレータを用いた接触動作 の制衔実験を示し，本制御法の有効性を示す。

\section{2. 作業座標の選択}

多関節形マニピュレータの運動方程式は，一般に， 次式で表される。

$$
M(q) \ddot{q}+h(q, \dot{q})=\tau_{q}
$$

ここで, $M(q): n \times n$ 慣性行列, $h(q, \dot{q}):$

$n$ ベタトル值関数, $q=\left[q_{1}, \cdots, q_{n}\right]^{T}$ : 関節座

標系, $\tau_{q}=\left[\tau_{q 1}, \cdots, \tau_{q n}\right]^{\top}:$ 舅節卜ルク

ロボットの自由度 $n$ は， $n \geqq 6$ を満たすものとする。 口ボットハンドの位置，万位を表す作羓座標 $r=\left[r_{1}\right.$, $\left.\cdots, r_{6}\right]^{r}$ は，qの関数として $r=r(q)$ で表せるから， ロボットハンドが拘束される拘束面 $\phi(r)=0$ は $\phi(q)$ $=0$ と畫いて一般性を失わない。ただし， $\phi=\left[\phi_{1}, \cdots\right.$,

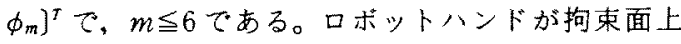
にあるときの運動方程式仗，

$$
M(q) \ddot{q}+h(q, \dot{q})=\tau_{q}+(\partial \phi / \partial q)^{T} \lambda
$$

で表すしとがでる。

$$
\begin{aligned}
& \text { ただし, } \\
& \lambda=\left[\lambda_{1}, \cdots, \lambda_{m}\right]^{r} \\
& (\partial \phi / \partial q)^{r}=\left[\begin{array}{lll}
\partial \phi_{1} / \partial q_{1} & \cdots & \partial \phi_{m} / \partial q_{1} \\
\partial \phi_{1} / \partial q_{n} & \cdots & \partial \phi_{m} / \partial q_{n}
\end{array}\right] \\
& \lambda: \text { フグランジュ乗数 }
\end{aligned}
$$

である。

拘束面上てい八イブリッド制推，すなわ方拘束面の 法線方向の力制御，接空間上での位置制衔を実行する ためには，座標系 $q$ は適切でない。そこで, 拘東面 上でのロボットの運動を記述するための新しい座標系 を導入する。それを， $\eta=\left[\eta_{1}, \cdots, \eta_{n}\right]^{T}$ と書く。ここで,

$$
\eta_{n-m+1}=\phi_{1}, \eta_{n-m+2}=\phi_{2}, \cdots, \eta_{n}=\phi_{m}
$$

とする。 $\left\{\eta_{1}, \cdots, \eta_{n-m}\right\}$ は拘束面に沿った座標である。

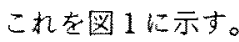

$$
\begin{gathered}
\text { 次に, } \eta_{1}, \cdots, \eta_{n-m} \text { の選び方を考える。 } \\
P=I-M^{-1}(q)(\partial \phi / \partial q)^{T} D^{-1}(\partial \phi / \partial q)
\end{gathered}
$$

と却く。たたし，

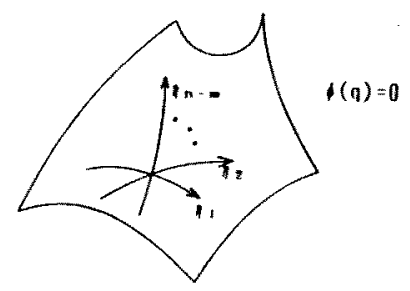

図 1 拘束面之座整系

Fig. 1. Constrained surface and coordinate system.

$$
D=(\partial \phi / \partial q) M^{-1}(q)(\partial \phi / \partial q)^{r}
$$

det $D \neq 0$ for $\forall q$

このとき,

$$
\begin{array}{ll}
\text { (i) } & P M^{-1}(q)(\partial \phi / \partial q)^{T}=0 \\
\text { (ii) } & (\partial \phi / \partial q) P=0 \\
\text { (iii) } & \operatorname{rank} P=n-m \text { for } \forall q
\end{array}
$$

が容易に示せる。（i ）（ iii ）より，Pは $R\left(M^{-1}(q)(\partial \phi / \partial q)^{T}\right]$ に㳂ったKer $[\partial \phi / \partial q]$ 人の射影行 列であ。更に，このことから，Pの独立な $n-m$ 本の列へタトルは，拘束面に対する接べクル空間を 作り，末た，Pの独立势 $n-m$ 本の行ベクトルは $M^{-1}(q)(\partial \phi / \partial q)^{T}$ と直交していることがわかる。従っ て, 求めるべ座標系 $\left\{\eta_{1}, \cdots, \eta_{n-m}\right\}$ 忧,

$$
d \eta_{i}=\left[\partial \eta_{i} / \partial q_{1}, \cdots, \partial \eta_{i} / \partial q_{n}\right] \quad(i=1, \cdots, n-m)
$$

とすれば，

$$
\operatorname{Span}\left\{d \eta_{1}{ }^{r}, \cdots, d \eta_{n-m}{ }^{r}\right\}=R(P]
$$

あるいは,

$$
\begin{aligned}
& \left\langle d \eta_{1}, g_{1}\right\rangle=0, \quad\left\langle d \eta_{1}, g_{2}\right\rangle=0, \cdots, \quad\left\langle d \eta_{1}, g_{m}\right\rangle=0 \\
& \left\langle d \eta_{n-m}, g_{1}\right\rangle=0,\left\langle d \eta_{n-m}, g_{2}\right\rangle=0, \quad\left\langle d \eta_{n-m}, g_{m}\right\rangle=0
\end{aligned}
$$

を満足しなければならない。ただし，

$\left\langle d \eta_{i}, g_{j}\right\rangle=\left(\partial \eta_{i} / \partial q_{1}\right) g_{j 1}+\cdots+\left(\partial \eta_{i} / \partial q_{n}\right) g_{j n}$,

$\left[g_{1}, \cdots, g_{m}\right]=M^{-1}(q)(\partial \phi / \partial q)^{T}, g_{j}=\left[g_{j 1}, \cdots, g_{j n}\right]^{T}$ と記す。 $\operatorname{Span}\{\cdot\}$ は, ベクトルト・\}によって張られる 空間を表し. $R[\cdot]$ は行列[・]の值域を表す。また, $\operatorname{Ker}[\cdot]$ は行列 [.] の零空間を示す。 $\left\{g_{1}, \cdots, g_{m}\right\}$ は, 互 いに独立なべクトルの集合であるから，この独立な心゙ クトルの集合 $\left\{g_{1}, \cdots, g_{m}\right\}$ に対して，独立なへクトル $\left\{e_{1}, \cdots, e_{n-m}\right\}$ を必ず見いだすことができる。なぜな ら，独立な $m$ 個の拘束条件 $\left\{\phi_{1}, \cdots, \phi_{m}\right\}$ に対して互い に独立な $n-m$ 個の拘束条件 $\left\{\phi_{m+1}, \cdots, \phi_{n}\right\}$ を任意に 与えることがでる。また， $M^{-1}(q)$ の正定性も一般 的に保障される。従って， 


$$
\begin{aligned}
e_{1} & =M^{-1}(q)\left(\partial \phi_{m+1} / \partial q\right)^{T}, \cdots, e_{n-m} \\
& =M^{-1}(q)\left(\partial \phi_{n} / \partial q\right)^{T}
\end{aligned}
$$

と扔けば（ 6 ）式を満たす独立なべクトル $\left\{e_{1}, \cdots, e_{n-m}\right\}$ を得ることができる。

$$
\operatorname{rank}\left[e_{1}, \cdots, e_{n-m}, g_{1}, \cdots, g_{m}\right]=n \quad \text { for } \forall q
$$

また， $e_{i}, g_{i}$ 忏すべて $q$ について解析的であるとす る。これらの条件の下で, Frobeniusの定理 ${ }^{(7)}$ 上り (5)式によって与えられた拘束面上の座標系 $\left(\eta_{1}, \cdots\right.$, $\left.\eta_{n-m}\right\}$ を以下の手順で求めることができる。

[ステップ1] 微分方程式 $d q / d s_{1}=e_{1}$ を 初期条件 $q(0)=0$ の下で解く。

【ステップ 2] 同様に, $d q / d s_{2}=e_{2}$ を 初期条件 $q\left(s_{1}, 0\right)=q\left(s_{1}\right)$ の下で解人。

【ステップ $n-m)$ 同様に, $d q / d s_{n-m}=e_{n-m}$ を 初期条件 $q\left(s_{\mathrm{i}}, \cdots, s_{n-m-1}, 0\right)=q\left(s_{1}, \cdots, s_{n-m-1}\right)$ の下て解く。

【ステップ $n-m+1$ ) 微分方程式 $d q / d t_{1}=g_{1}$ を 初期条件 $q\left(s_{1}, \cdots, s_{n-m}, 0\right)=q\left(s_{1}, \cdots, s_{n-m}\right)$ の下で解く。

〔ステップ $n-m+i\}$ 微分方程式 $d q / d t_{i}=g_{i}$ 初期条件 $q\left(s_{1}, \cdots, s_{n-m}, t_{1}, \cdots, t_{i-1}, 0\right)=$ $q\left(s_{1}, \cdots, s_{n-m}, t_{1}, \cdots, t_{i-1}\right)$

の下で解く。

(ステップ $n$ ) 微分方程式 $d q / d t_{m}=g_{m}$ を 初期条件 $q\left(s_{1}, \cdots, s_{n-m}, t_{1}, \cdots, t_{m-1}, 0\right)=$ $q\left(s_{1}, \cdots, s_{n-m}, t_{1}, \cdots, t_{m-1}\right)$

の下で解く。

以上の手順上り，関節座標空間 $\left\{q_{1}, \cdots, q_{n}\right\}$ とハラ メー夕空間 $\left\{s_{1}, \cdots, t_{m}\right\}$ との間の射影開係が定義でき たすすなっち,

$$
\left[\begin{array}{c}
q_{1} \\
\cdot \\
\cdot \\
q_{n}
\end{array}\right]=\left[\begin{array}{l}
q_{1}\left(s_{1}, \cdots, s_{n-m}, t_{1}, \cdots, t_{m}\right) \\
\cdot \\
\cdot \\
q_{n}\left(s_{1}, \cdots, s_{n-m}, t_{1}, \cdots, t_{m}\right)
\end{array}\right]
$$

である。

（7）式にお゙いて，（6)式の条件を用いれば, 行列

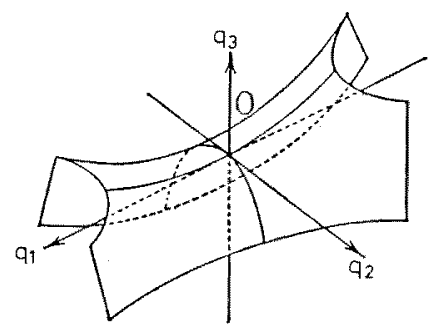

圆 2 双曲放物面

Fig. 2. Hyperbolic parabora.

$$
\begin{aligned}
& T= \\
& {\left[\begin{array}{cccc}
\partial q_{1} / \partial s_{1} \cdots & \partial q_{1} / \partial s_{n-m} & \partial q_{1} / \partial t_{1} \cdots & \partial q_{1} / \partial t_{m} \\
\cdot & \cdot & \cdot & \cdot \\
\cdot & \cdot & \cdot & \cdot \\
\cdot & \cdot & \cdot & \cdot \\
\partial q_{n} / \partial s_{1} \cdots \partial q_{n} / \partial s_{n-m} & \partial q_{n} / \partial t_{1} \cdots & \partial q_{n} / \partial t_{m}
\end{array}\right]}
\end{aligned}
$$

は，常に $\operatorname{rank} T=n か ゙$ 成り立つため，逆関数定理に 上って原点近傍で, $s_{3}, \cdots, s_{n-m}, t_{1}, \cdots, t_{m}$ 吱関穊座摽 系 $q$ について解ける。このとき， $\eta_{1}=s_{1}, \eta_{2}=s_{2}, \cdots$, $\eta_{n-m}=s_{n-m}$ とおけば

$$
d \eta_{i} / d t_{j}=0 \quad(i=1, \cdots, n-m, \quad j=1, \cdots, m)
$$

となり，この $\eta_{1}, \cdots, \eta_{n-m}$ が求める拘束面上の座標で ある。なぜら、

$$
\begin{aligned}
\left\langle d \eta_{i}, g_{i}\right\rangle= & \left\langle d \eta_{i}, d q / d t_{j}\right\rangle \\
= & \partial \eta_{i} / \partial q_{1} \cdot d q_{1} / d t_{j}+\cdots \\
& +\partial \eta_{i} / \partial q_{n} \cdot d q_{n} / d t_{j} \\
= & d \eta_{i} / d t_{j}=0 \\
& (i=1, \cdots, n-m, \quad j=1, \cdots, m)
\end{aligned}
$$

次に，例題を用いて，上記の手覑を確認する。

〔例 題〕簡単のため, (1) 式の $M(q)$ は単位行 列とする。图 2 に拘束条件示方。その方程式は

$$
\phi_{1}=q_{3}-q_{1}^{2} / a^{2}+q_{2}^{2} / b^{2}
$$

である。こ虬に対して独立な仮想拘柬条件を

$$
\phi_{2}=q_{1}-c_{1}, \quad \phi_{3}=q_{2}-c_{2}
$$

とすれ活，

$$
g_{1}=\left[\begin{array}{c}
-2 q_{1}^{0} / a^{2} \\
2 q_{2}^{0} / b^{2} \\
1
\end{array}\right], \quad e_{1}=\left[\begin{array}{l}
1 \\
0 \\
0
\end{array}\right], \quad e_{2}=\left[\begin{array}{l}
0 \\
1 \\
0
\end{array}\right]
$$

を得る。 $q^{0}=\left[q_{1}^{0}, q_{2}{ }^{0}\right]^{T}$ 浩, 拘束条件上の局所座標采 $\eta_{1}, \eta_{2}$ 求めるため0座標原点でる。

先の手順より次のように座標系が求まる。

[ステップ 1] $d q / d s_{1}=e_{1}$ を初期条件 $q(0)=0$ の下で解けば $q=\left(s_{1}, 0,0\right)^{r}$ を得る。 
【ステップ2〕 $d q / d s_{2}=e_{2}$ を初期条件 $q\left(s_{1}, 0\right)$ $=q\left(s_{1}\right)$ の下で解けば $q=\left[s_{1}, s_{2}, 0\right]^{T}$ を得る。

(ステップ 3) $d q / d t_{1}=g_{1}$ を初期条件 $q\left(s_{1}, s_{2}\right.$, $0)=q\left(s_{1}, s_{2}\right)$ の下で解けば $q=\left[s_{1}-2 q_{1}^{0} t_{1} / a^{2}, s_{2}\right.$ $\left.+2 q_{2}^{0} t_{1} / b^{2}, t_{1}\right]^{T}$ を得る。これより， $t_{1}=q_{3}, s_{1}=q_{1}$ $+2 q_{1}{ }^{0} q_{3} / a^{2}, s_{2}=q_{2}-2 q_{2}{ }^{0} q_{3} / b^{2}$ を得る。従って, 曲面 上の座標系として

$$
\begin{aligned}
& \eta_{1}=s_{1}=q_{1}+2 q_{1}^{0} q_{3} / a^{2} \\
& \eta_{2}=s_{2}=q_{2}-2 q_{2}^{0} q_{3} / b^{2} \\
& \eta_{3}=\phi_{1}
\end{aligned}
$$

を選べばよい。これは, 明らかに, $\left\langle d \eta_{1}, g_{1}\right\rangle=0$, $\left\langle d \eta_{2}, g_{1}\right\rangle=0$ を満足する。

\section{3. 制御系の構成}

前章で与えられる座標系 $\eta$ は, $n$ 次元多様体 $N$ 上 で定義されるものであるため，それぞれ，

$$
\begin{aligned}
& q^{0}=\left[q_{1}{ }^{0}, \cdots, q_{n}{ }^{0}\right]^{T}, q_{1}=\left[q_{1}{ }^{1}, \cdots, q_{n}{ }^{1}\right]^{T}, \cdots, \\
& q^{i}=\left[q_{1}{ }^{i}, \cdots, q_{n}{ }^{1}\right]^{T}
\end{aligned}
$$

の各座標原点上で局所的に与えられるものである。従 って, 局所座標 $\eta$ は, $\eta=\eta\left(q, q^{i}\right), \quad i=0,1, \cdots$ とし て, サンプリングごとに, 座標系クも更新されなけ ればならない。しかし， $\eta=\eta\left(q, q^{i}\right)$ において，q にかんする構造は， $N$ 上では不変であるため，サン プリングごとに観測される $q^{i} の$ 值を用いて容易にク を定めることができる。

拘束面での座標系 $\left[\eta_{1}, \eta_{2}, \cdots, \eta_{n}\right]^{T}$ が与之られれば, これに対して, 次のように制御系の構成が可能とな る。まず，座標系 $\left[\eta_{1}, \cdots, \eta_{n}\right]^{T}$ の時間に関する二階微 分をとる。

$$
\ddot{\eta}=[\partial \eta / \partial q] \ddot{q}+d / d t[\partial \eta / \partial q] \dot{q}
$$

ただし，

\section{$[\partial \eta / \partial q]$}

$$
\begin{gathered}
{\left[\begin{array}{cc}
\partial \eta_{1} / \partial q_{1} & \partial \eta_{1} / \partial q_{2} \cdots \\
\vdots & : \\
\partial \eta_{n-m} / \partial q_{1} & \partial \eta_{n-m} / \partial q_{2} \cdots \\
\hdashline \partial \eta_{n-m+1} / \partial q_{1} & \partial \eta_{n-m+1} / \partial q_{2} \cdots \\
\vdots & \vdots \\
\partial \eta_{n} / \partial q_{1} & \partial \eta_{n} / \partial q_{2} \cdots \\
\partial \eta_{1} / \partial q_{n} \\
\vdots \\
\partial \eta_{n-m} / \partial q_{n} \\
\hdashline \partial \eta_{n-m+1} / \partial q_{n} \\
: \\
\partial \eta_{n} / \partial q_{n}
\end{array}\right]=\left[\begin{array}{l}
\partial \eta_{f} / \partial q \\
\partial \eta_{c} / \partial q
\end{array}\right]}
\end{gathered}
$$

とする。ただし，

$$
\eta_{f}=\left[\eta_{1}, \cdots, \eta_{n-m}\right]^{T}, \quad \eta_{c}=\left[\eta_{n-m+1}, \cdots, \eta_{n}\right]^{T}
$$

とする。

(8)式を(2)式を用いて書きなおすと,

$$
\begin{aligned}
\ddot{\eta}= & {[\partial \eta / \partial q]\left\{M ^ { - 1 } ( q ) \left(-h(q, \dot{q})+\tau_{q}\right.\right.} \\
& \left.\left.+(\partial \phi / \partial q)^{T} \lambda\right)\right\}+d / d t[\partial \eta / \partial q] \dot{q} .
\end{aligned}
$$

である。ここで, 関節トルクを

$$
\tau_{q}=\left(\partial \eta_{f} / \partial q\right)^{T} u_{1}+\left(\partial \eta_{c} / \partial q\right)^{T} u_{2}
$$

とする。このとき, (9)式は,

$$
\begin{aligned}
\ddot{\eta}_{f}= & -\left(\partial \eta_{f} / \partial q\right) M^{-1}(q) h(q, \dot{q}) \\
& +d / d t\left(\partial \eta_{f} / \partial q\right) \dot{q} \\
& +\left(\partial \eta_{f} / \partial q\right) M^{-1}(q)\left(\partial \eta_{f} / \partial q\right)^{T} u_{1} \\
\ddot{\eta}_{c}= & -\left(\partial \eta_{c} / \partial q\right) M^{-1}(q) h(q, \dot{q}) \\
& +d / d t\left(\partial \eta_{c} / \partial q\right) \dot{q} \\
& +\left(\partial \eta_{c} / \partial q\right) M^{-1}(q)\left(\partial \eta_{c} / \partial q\right)^{T}\left(u_{2}+\lambda\right)
\end{aligned}
$$

となる。(11)式は, 拘束面上の座標系で記述された口 ボットの運動方程式である。これよりロボットの拘束 運動は, 二つの座標系 $\left\{\eta_{f}\right\}$ と $\left\{\eta_{c}\right\}$ に関する運動へと 分離できることが示された。

座標系 $\left\{\eta_{f}\right\},\left\{\eta_{c}\right\}$ の独立性と $M(q)$ の正則性から

$$
\begin{aligned}
& \operatorname{det}\left[\left(\partial \eta_{f} / \partial q\right) M^{-1}(q)\left(\partial \eta_{f} / \partial q\right)^{T}\right] \neq 0 \\
& \operatorname{det}\left[\left(\partial \eta_{c} / \partial q\right) M^{-1}(q)\left(\partial \eta_{c} / \partial q\right)^{T}\right] \neq 0
\end{aligned}
$$

である。(11)式で, $\lambda$ はラグランジュ乗数と呼ばれ， 物理的には接触面の法線方向に働く反力である。この 值は $\phi=\dot{\phi}=\ddot{\phi}=0$ であれば, 解析的に求めること ができる(6)。しかし，実際の接触作業では， $\phi=\dot{\phi}=$ $\ddot{\phi}=0$ とはなり得ない。この場合, $\lambda(t)$ の值は, 力七 ンサによって得られるものとする。従って，斿を

$$
\begin{aligned}
u_{2}= & {\left[\left(\partial \eta_{c} / \partial q\right) M^{-1}(q)\left(\partial \eta_{c} / \partial q\right)^{T}\right]^{-1} } \\
& \times\left\{\left(\partial \eta_{c} / \partial q\right) M^{-1}(q) h(q, \dot{q})\right. \\
& \left.-d / d t\left(\partial \eta_{c} / \partial q\right) \cdot \dot{q}+\phi\left(\eta_{c}, \dot{\eta}_{c}, \Delta u\right)\right\}-\lambda
\end{aligned}
$$

とおけば，拘束面の法線方向には

$$
\ddot{\eta}_{c}=\phi\left(\eta_{c}, \dot{\eta}_{c}, \Delta u\right)
$$

が成り立つ。

(13)式で， $\Delta u$ は希望反力であり， $\phi\left(\eta_{c}, \eta_{c}, \Delta u\right) に$ よって, 反力 $\Delta u$ と拘束面座標 $\eta_{c}$ に関するインピー ダンスを任意に設定することができる。

しかし，入力 $u_{2}$ を

$$
\begin{aligned}
u_{2}= & {\left[\left(\partial \eta_{c} / \partial q\right) M^{-1}(q)\left(\partial \eta_{c} / \partial q\right)^{T}\right]^{-1} } \\
& \times\left\{\left(\partial \eta_{c} / \partial q\right) M^{-1}(q) h(q, \dot{q})\right. \\
& \left.-d / d t\left(\partial \eta_{c} / \partial q\right) \dot{q}+\phi\left(\eta_{c}, \dot{\eta}_{c}\right)\right\}
\end{aligned}
$$

とすれば 


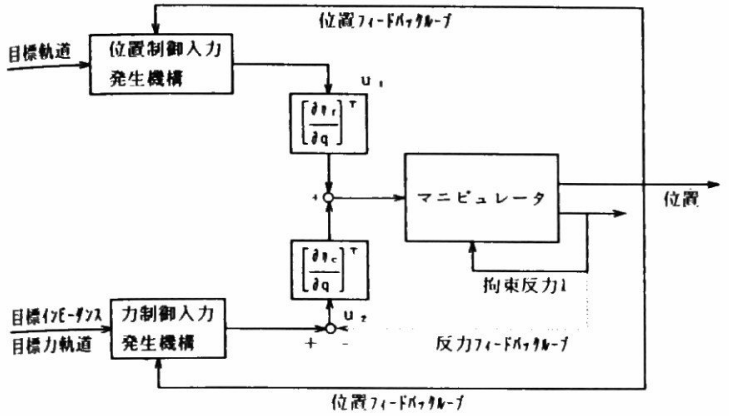

図 3 ハイブリッド制御系

Fig. 3. Hybrid control system.

$$
\ddot{\eta}_{c}=\phi\left(\eta_{c}, \dot{\eta}_{c}\right)+\left(\partial \eta_{c} / \partial q\right) M^{-1}(q)\left(\partial \eta_{c} / \partial q\right)^{T} \lambda
$$

となり, 接触反力 $\left(\partial \eta_{c} / \partial q\right) M^{-1}(q)\left(\partial \eta_{c} / \partial q\right)^{T} \lambda$ の下での インピータ゚ンス制御が実行できる。接触反力の正確な 検出は困難であることから，拘束面の法線方向には， このような制御系を構成するほうがより現実的で ある。

一方， $\eta_{f}$ に関しては $u_{1}$ を次式のように選べば，任 意の位置制御が可能である。

$$
\begin{aligned}
u_{1}= & {\left[\left(\partial \eta_{f} / \partial q\right) M^{-1}(q)\left(\partial \eta_{f} / \partial q\right)^{T}\right]^{-1} } \\
& \times\left\{\left(\partial \eta_{f} / \partial q\right) M^{-1}(q) h(q, \dot{q})\right. \\
& \left.-d / d t\left(\partial \eta_{f} / \partial q\right) \cdot \dot{q}+\psi(t)\right\} \cdots .
\end{aligned}
$$

(11)式より

$$
\ddot{\eta}_{f}=\psi(t)
$$

が成り立つ。

以上をまとめて, 次の結果を得る。

(結 果) 座標系 $\left[\eta_{1}, \cdots, \eta_{n}\right]^{T}$ に対して

$$
\eta_{n-m+1}=\phi_{1}, \cdots, \eta_{n}=\phi_{m} \quad\left(\eta_{c}=\phi\right)
$$

とする。 $\eta_{f}=\left[\eta_{1}, \cdots, \eta_{n-m}\right]^{T}$ に関しては，前章で述べ た手順に従い決定する。

関節トルク $\tau_{q}$ を

$$
\tau_{q}=\left(\partial \eta_{f} / \partial q\right)^{T} u_{1}+\left(\partial \eta_{c} / \partial q\right)^{T} u_{2}
$$

と置き， $u_{1}, u_{2} を(12),(16)$ 式のように置けば

$$
\begin{aligned}
& \ddot{\eta}_{f}=\phi(t) \\
& \ddot{\eta}_{c}=\phi\left(\eta_{c}, \dot{\eta}_{c}, \Delta u\right)
\end{aligned}
$$

となり，位置と力の制御が実現できる。

図 3 にこの制御系の構成図を示す。

\section{4. 実験 結果}

本論文で提案するハイブリッド制御系の構成法を立 証するために, 図 4 に示される実験システムで実験を 行った。これは, 2 自由度マニピュレータによる接触

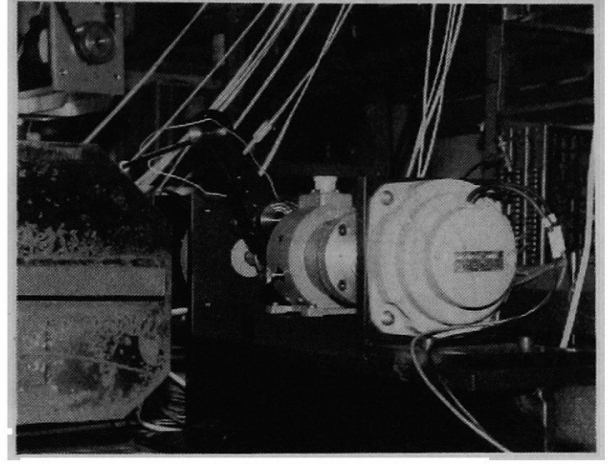

図 42 自由度マニピュレー夕

Fig. 4. Two degrees of freedom manipulator.

動作を表している。マニピュレータの先端には，プラ スチック製の車輪が装着され, 対象物面を滑らかに移 動できる。更に, 先端の車輪近くに，2枚のひずみゲ ージを張り, 接触時の反力情報を検出できるようにな っている。マニピュレータの関節角 $q_{1}, q_{2}$ は, ポテン ショメータで検出され, それぞれ $100 \mathrm{~W}$ のプリント モータ (安川製), 小形直流モータLN 22-00703 (CANON 製) で駆動される。このシステムの運動方 程式は同定実験によって，次式で与えられる。

$$
\begin{array}{r}
{\left[\begin{array}{cc}
0.035 & 0 \\
0 & 0.109
\end{array}\right]\left[\begin{array}{l}
\dot{q}_{1} \\
\dot{q}_{2}
\end{array}\right]+\left[\begin{array}{l}
0.122 \operatorname{sgn}\left(\dot{q}_{1}\right) \\
0.0439 \operatorname{sgn}\left(\dot{q}_{2}\right)
\end{array}\right]} \\
+\left[\begin{array}{c}
-0.3 \sin \left(q_{1}\right) \\
0
\end{array}\right]=\left[\begin{array}{l}
v_{1} \\
v_{2}
\end{array}\right] \ldots \ldots \cdots \cdots(18)
\end{array}
$$

ここで, $v_{1}, v_{2}$ は各々のサーボモータへエネルギー を供給するパワーアンプ MODEL BPA-353 (メトロ ニクス製)，MODEL POW 35-5 (菊水製) に加えら れる電圧信号である。慣性力とコリオリ, 遠心力は, すべて外乱として無視した。

図 5 に示すように $q_{1}$ の回転中心を座標原点にとれ ば, マニピュレータの先端座標 $(X, Y)$ は, 次式で与 えられる。

$$
\begin{aligned}
& X=l_{1} \sin \left(q_{1}\right)+l_{2} \sin \left(q_{1}+q_{2}\right) \\
& Y=l_{1} \cos \left(q_{1}\right)+l_{2} \cos \left(q_{1}+q_{2}\right)
\end{aligned}
$$$$
\text { ただし， } l_{1}=13.5 \mathrm{~cm}, l_{2}=9 \mathrm{~cm} \text { である。 }
$$

この $(X, Y)$ 座標は, 拘束条件

$$
a X+b Y-1=0
$$

を満足しなければならない。ここで, $a=10.2, b=$ 9.5 である。 $\phi_{1}=a X(q)+b Y(q)-1$ として, 第 2 章 で示した手順に従って，拘束面上の座標系を定める。 ここで， $\phi_{1}$ と独立な仮想拘束条件として， $\phi_{2}=-b X$ $+a Y-1$ を選ぶ。第 2 章の手順より, $\eta_{1}, \eta_{2}$ が次の 


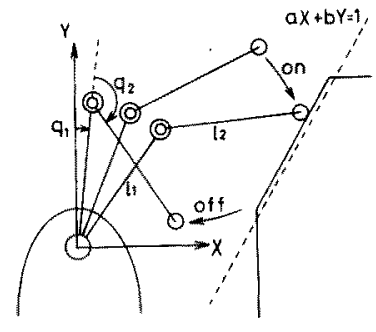

図 5 拘束運動

Fig. 5. Constrained manipulation.

ように求まる。

$$
\begin{aligned}
& \eta_{1}=\left\{p_{2}(i) q_{1}-p_{1}(i) q_{2}\right\} / D(i) \\
& \eta_{2}= \phi_{1}(q) \\
& p_{1}(i)= a\left\{l_{1} \cos \left(q_{1}{ }^{i}\right)+l_{2} \cos \left(q_{1}{ }^{i}+q_{2}{ }^{i}\right)\right\} \\
&-b\left\{l_{1} \sin \left(q_{1}{ }^{i}\right)+l_{2} \sin \left(q_{1}{ }^{i}+q_{2}{ }^{i}\right)\right\} \\
& p_{2}(i)= a l_{2} \cos \left(q_{1}{ }^{i}+q_{2}{ }^{i}\right)-b l_{2} \sin \left(q_{1}{ }^{i}+q_{2}{ }^{i}\right) \\
& D(i)= q_{1}{ }^{i} p_{2}(i)-q_{2}{ }^{i} p_{1}(i)
\end{aligned}
$$$$
\text { ただし， }
$$

(結果)を用いて，制御入力 $v$ を次のように与える。

$$
v=K\left[\left(\partial \eta_{1} / \partial q\right)^{r} u_{1}+\left(\partial \eta_{2} / \partial q\right)^{r} u_{2}\right]
$$

ただし，

$$
\begin{aligned}
& K=\operatorname{diag}(0.035, \quad 0.109) \\
& u_{1}=\left\{\left(\partial \eta_{1} / \partial q\right)\left(\partial \eta_{1} / \partial q\right)^{T}\right]^{-1}\{\xi(t)\} \\
& u_{2}=\left[\left(\partial \eta_{2} / \partial q\right)\left(\partial \eta_{2} / \partial q\right)^{T}\right]^{-1}\left\{a \eta_{2}\right\}
\end{aligned}
$$

こ机らの演算は，スーパミニコン DS 600/40 (東芝 製)を用いて，サンプリング時間 $16.2 \mathrm{~ms}$ で害現さ れる。

図 5 に赛験の樣子を示す。このように，ある任意の 初期位置より拘束面へと引き込まれ，拘束面上を約 $10 \mathrm{~cm}$ 直線的に移動し, 端点で拘束面から離れる。こ の間, 制御入力は (19)式で与えられ, 力制御モード, 位 置制御モードのモード切換えを行わずに位置と力の制 御が達成される。図6はこのときのひずみゲージの出 力を示す。(a)図はフィードバックダイン $a=-10$ の場合で，(b)図は $a=-15$ の場合の接触トルクを 示している。この図の縦の目盛 $1 \mathrm{~cm}$ は, $0.03 \mathrm{~kg} \cdot \mathrm{cm}$ のひずみ量を示し，横軸 $1 \mathrm{~cm}$ は $10 \mathrm{~s} の$ 時閵推移を示 す。この結果に示されるように, 拘束面の法線方向に 設定されたインピーダンスによって柔軟な接触作業が 達成されている。(19)式で明らかなように，この制御 系では力フィードバックを行っていない。を机にもか かわらず，接触時に抢いて強い衝撃が加わることなく

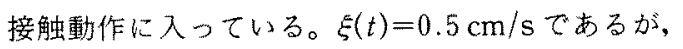
接触抵抗のため，その速度は必ずしも設定スピードに

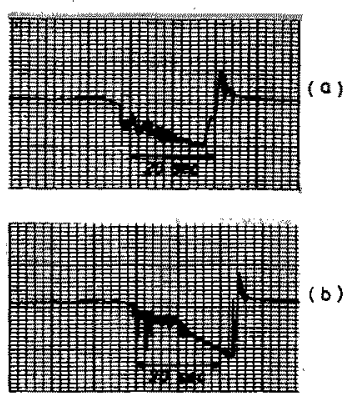

図 6 実験結果

Fig.6. Experimental result.

は一致していない。これに対しては，接空間方向への フィードバックゲインを大きくすることによって，十 分対応できると考えられる。また，接触卜ルクが直線 的に増加しているが，これに対しても，力フィードバ ックを行うことによって，一定の接触トルクによる作 業も可能である。これらの点については, 今後更に実 験的検討を加える必要がある。

\section{5. 終りに}

ハイブリッド制御系の構成法について述べた。本論 文で述べた構成法は, 拘束面の法線方向と接空間方向 に座標系を分離する手法に基づいている。更に, 法線 方向に対しては、インピーダンスを調整できるような 制御系になっている。そのため、制御モードの切換え が不必要であり，また力フィードバックを必要とせず に滑らかな接触作業が実現できる制御系が構成で きた。

今後，更に実験的検討を加えることによって，自由 度の大きなロボットマニピュレータに対しても十分適 用可能な制御系であることを実証することが重要であ る。その際, 問題となるのが制御則そのもののもつ襩 雑さである。この問題は、制御系のロバスト性とも密 接にかかわってくるものであり, 今後, 実装化にあた って更に検討を加えたい。（平成 2 年 3 月 26 日受付)

\section{文献}

(1) N. Hogan: Impedance Control: "An approach to manipu. lation. Part $1 \sim 11^{*}$. Thans. ASME J. Dunamic Sysi.. Meas. Control, 107. 1 (1985)

(2) H. Kazarooni, et al: "Robust Compliant Motion for Manipulations. Part I, II", IEEE J. Robotics \& Automo fion. RA-2.83 (1986)

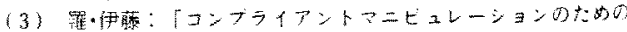

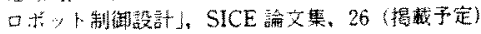

(4) M.H. Raibert \& J.J. Craig: "Hybrid Position/Force Control of Manipulators". Trans. ASME J. Dimanic Syst. Meas. Commol. 102. 126 (1981)

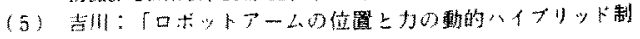


御了, ロポット学誌, 3, 25 (昭60)

（6）成清・伊漛・細江：「拘束条件付力学系の一解法」, SICE 論 文集, 18. 55 (昭 57)

（7）松島：多様体入門（昭 51）裳華房

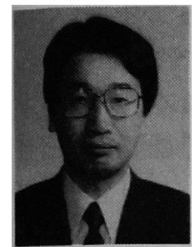

\section{成 清 辰 生（正員）}

昭和 27 年 7 月 27 日生。 53 年 3 月名古屋大学工学部応用物理学科卒 業。5 8 年 3 月名古屋大学情報工学 専攻博士課程単位取得中退。同年 4 月通産省工業技術院九州工業技術試験所入所。62 年 9 月〜 63 年 9 月アメリカ合衆国・オハイオ州立大学客 員研究員。平成 2 年 4 月豊田工業大学助教授。ロポッ
トの制御技術に関する研究に従事。工学博士。計測自 動制御学会会員。

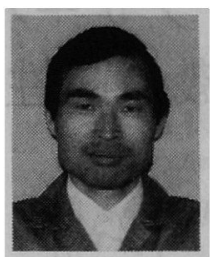

$$
\text { 泉照之(正員) }
$$

昭和 21 年 12 月 14 日生。 46 年 3 月広島大学工学部電子工学科卒業。 同年 4 月通産省工業技術院九州工業 技術試験所に入所。平成元年 4 月山 口大学工学部助教授。不規則信号の発生法や検出法, ロボットの視覚や力覚の信号処理に関する研究に従 事。工学博士。日本ロボット学会, 計測自動制御学 会, 情報処理学会, 日本音響学会会員。 